\title{
CRISIS MANAGEMENT AND OPERATIONAL RISK MANAGEMENT IN THE FINANCIAL SECTOR IN THE SHADOW OF COVID-19'
}

\author{
Zsuzsanna Tamásné Vőneki
}

\begin{abstract}
This paper presents the definition of crisis and the approaches of crisis management, concentrating on the phases, key tasks and responses of corporate crisis management applicable to the current pandemic, with a special focus on financial institutions. Beyond health protection, the main objective of corporate crisis management during a pandemic is to maintain business continuity and improve - or at least protect - a given company's reputation and preserve its customer base. The company needs to provide three types of response to a crisis: operational, management and communication responses. The current COVID-19 pandemic has changed banks' operational risk portfolios, increasing the probability of risk types such as cyber, outsourcing and fraud risks. Financial institutions and other organisations need to improve their early warning systems to recognise these threats in time.
\end{abstract}

JEL codes: G200, G21

Keywords: crisis management, COVID-19, operational risk, banking

\section{INTRODUCTION}

The relevant literature on risk management distinguishes risk - i.e. events that can be described by probability distributions - from uncertainty, which is beyond our forecasting capabilities (Bélyácz, 2013). Most crises belong to the universe of uncertainty; however, risk professionals and organisations still try to do their best to enter this universe and predict the unpredictable. As a result, more and more

1 This research was supported by the Higher Education Institutional Excellence Program of the Ministry of Human Capacities, within the framework of the 'Financial and Public Service' research project (NKFIH-1163-10/2019) at Corvinus University of Budapest.

2 Zsuzsanna Tamásné Vöneki, Department of Finance, Corvinus University of Budapest; OTP Bank Nyrt., Operational Risk Department. E-mail: zsuzsanna.voneki@uni-corvinus.hu. 
events are transferred from the category of uncertainty to that of risk. The same has happened with operational risks and crisis events.

Forty years ago, a pandemic like the current COVID-19 would have been categorised as an uncertainty event. Today, the operational risk management teams of financial institutions regularly evaluate the development of these scenario-level risks and the possibility of preparing for them. Consequently, every bank now has a pandemic scenario which serves to evaluate the possibility of a pandemic and its impact on banking operations.

Managing scenario-level events - such as natural disasters, IT system breakdown, significant internal fraud, money laundering or a pandemic - is the responsibility and task of crisis management and business continuity management departments.

Talking about crisis and business continuity management in "peacetime" and forcing the organisation to devote resources to crisis preparedness is a challenging task. However, if we start dealing with crisis preparation only when a crisis arises, it is already too late to avoid financial, reputational and other losses.

The last two decades, with events such as the global economic crisis of 2007/2008 or the ongoing crisis caused by the COVID-19 pandemic, have provided a wealth of experience and learning opportunities in crisis management.

It might seem ambitious to write about a current pandemic with scientific sophistication whilst the crisis is still ongoing, but both the scientific community and practitioners need information and analyses that can contribute to their efforts.

At the end of 2019 and in the first months of 2020, several scientific articles were published on the topic, but they mainly approached the virus from a medical point of view (Wei et al., 2020) or focused on the expected economic consequences in the countries concerned (Correia et al., 2020).

This article goes one step further and examines the issue from the perspective of corporates and corporate crisis management. Although corporate risk management can only handle the recent situation in accordance with the current government measures, some practices and preparatory steps are still necessary in order to avoid further damage.

The next chapter discusses the definition of crisis and the scientific approach to crisis management. The third chapter deals with the issues addressed by crisis management. In the fourth chapter, we discuss the tasks required in the three phases of the crisis during the current pandemic situation, highlighting specific aspects of the banking sector. In the fifth chapter, we concentrate on changes in the banking operational risk portfolio caused by the current crisis. Although the article contains interesting findings for companies in all sectors, we present 
the topics outlined within a banking risk management and crisis management framework.

\section{CRISIS AND CRISIS MANAGEMENT}

The term 'crisis' can be defined at various levels: at least at the individual, organisational, national or social levels. Although the main characteristics of a crisis and its processes show similarities at several levels, this paper focuses on the organisational level. Hendershott et al. (2015) define a crisis as an "unexpected value-destroying event." Pearson and Clair (1998) consider the psychological, socialpolitical and technological-structural dimension of a crisis in creating a complex definition: "An organisational crisis is a low-probability, high-impact situation that is perceived by critical stakeholders to threaten the viability of the organisation and that is subjectively experienced by these individuals as personally and socially threatening." Bundy et al. (2016) conducted a review of the literature in the most relevant management and communication journals and found that crisis and crisis management are interdisciplinary subjects that cover the areas of strategy management, organisational theory, organisational behaviour, public relations and corporate communications. Based on their article, an organisational crisis is "an event perceived by managers and stakeholders as highly salient, unexpected, and potentially disruptive." This definition reflects an approach that holds that, in the era of social media, an organisation can face a crisis at any time and for no fundamental reason (Phillips, 2013).

The previously mentioned research provides evidence that the definition of a crisis can derive from several theories or fields. Nevertheless, the different definitions share some common points:

- The event happens suddenly, at least for some stakeholders. At an internal fraud case, some leaders may realise the problem very early, but for other stakeholders (customers, investors) it is a sudden event.

- The event threatens the financial situation or reputation of the organisation, or at least some stakeholders may perceive it as a threatening situation. Social media have reduced the capability of an organisation to protect its reputation in the event of a crisis; however, at the same time, they also provide a new tool and network for crisis management (Veil et al., 2011).

- Information has become public. In the case of Volkswagen - when emission reports were faked and cars seemed more environmentally friendly than they really were - the problem evolved into a crisis event only after it had become public, regardless of the fact that an investigation by West Virginia University pointed out the problem at least one year before (Bachmann et al., 2017). 
- The situation cannot be handled by normal organisational processes or through normal communication activity.

If we categorize the operational risks based on probability-impact and couple them with possible risk reduction/handling/avoidance measures, we can draw the following:

\section{Figure 1}

\section{Operational risks and their handling}

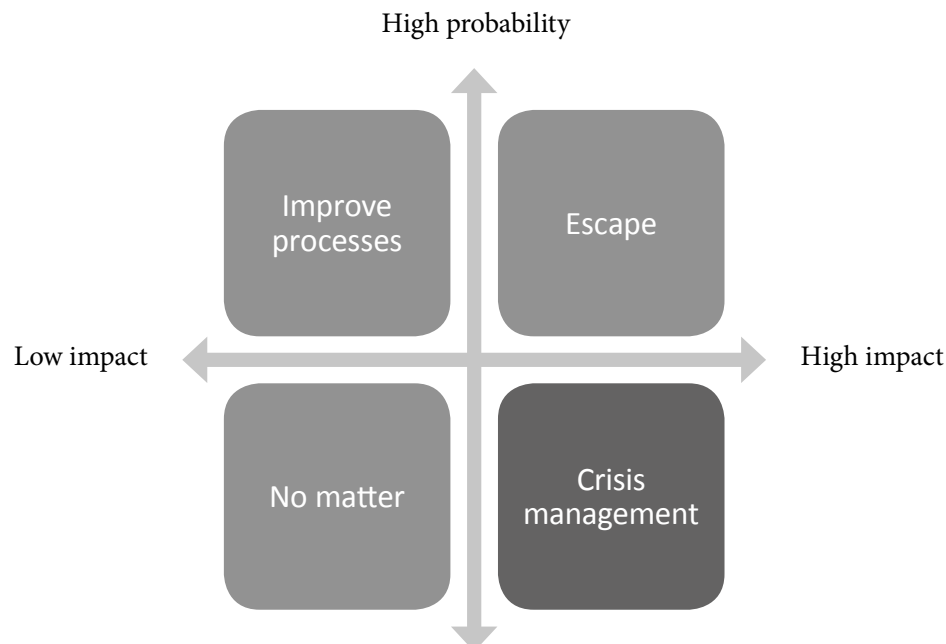

Low probability

Source: own design

If we examine the organisational crisis events of the past few years that had a serious impact on the capital and reputation of the institutions involved, we see that most of them were high-impact/low-probability operational risks, such as the Royal Bank of Scotland's IT breakdown in 2012 (BBC, 2014), the political conflict between Russia and Ukraine, the terrorist attacks all over Europe, big internal fraud cases (Barings, Volkswagen) or natural catastrophes (e.g. the floods in Europe in 2013).

If we look at the current pandemic, there is no doubt that it falls into the category of crisis. By the end of August 2020, the epidemic had broken out in almost every country, causing more than 24.7 million infections and 837,000 deaths (Johns Hopkins, 2020). There is no doubt that it is a public, devastating event that requires an immediate response; at the same time, though rare, it is affecting the overall operation of companies, causing significant financial losses. In this case, a 
company can suffer reputational loss if its crisis management is of a lower standard than expected by stakeholders, or even fails.

After defining the crisis, our next goal is the examination of crisis management. The purpose of corporate crisis management is to identify and manage situations that threaten an organisation's financial or reputational position. One of the best summary studies is the work of Bundy et al. (2016), which classifies corporate crisis management studies into two groups; namely researchers supporting external approaches, and scholars who favour internal approaches. Authors with the internal perspective emphasize the importance of corporate preparedness, leadership during a crisis and organisational learning, while those taking the external perspective see that successful crisis management lies in dealing with stakeholders and approaching their expectations and therefore the social reception of their crisis management efforts.

Crisis management in practice typically uses aspects and tools from both approaches, as shown in the following chapters.

\section{SPECIFICATION OF A PANDEMIC SITUATION}

As mentioned before, the current pandemic situation undoubtedly meets the definition criteria of a crisis. Furthermore, it causes a crisis on all three levels social, corporate and individual - and is therefore a situation that requires crisis management responses. The main parameters of previous influenza epidemics are shown in Figure 2.

\section{Figure 2}

Flu pandemic history

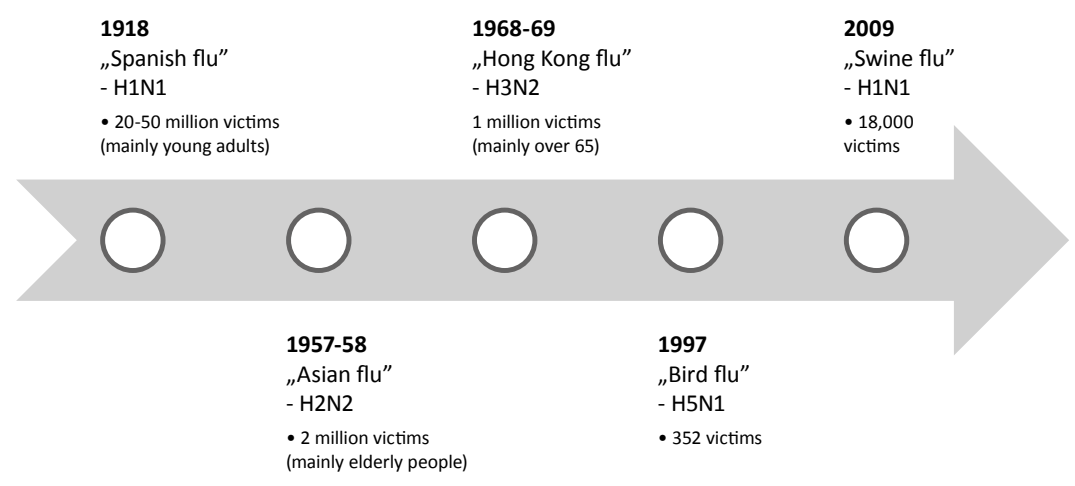

Source: own design (based on CDC 2020/a) 
Although it is not the purpose of this study to examine the economic and other effects of previous epidemics, we can conclude that COVID-19, unlike the epidemics of the last 30 years, has not only local impacts, but also serious consequences for all segments of the economy and society. In many cases, the epidemiological measures themselves have negative economic and social consequences.

Crisis management actions and processes at social and governmental level are regular topics of the daily press and scientific journals. Governments concentrate on both the health crisis itself and the economic and social consequences of restrictive measures. In addition, individual crisis management - maintaining the physical, mental and emotional health of citizens, and protecting individual or family livelihoods - is also within the focus of government attention. The effects of the pandemic can be particularly negative for already disadvantaged families, which - in addition to struggling for a daily living - have greater difficulty accessing information and help in order to manage their individual crises. Bennett and Carney (2015) identified two types of vulnerability: health and economic vulnerability. Reviewing previous cases of pandemics, they identified five main lessons, one of which was the importance of protecting individuals who are vulnerable in any way.

We know less about corporate crisis management. Some professional organisations and consulting firms (McKinsey, 2020) have issued recommendations that can be used to compile a set of aspects that corporate crisis management should consider in a pandemic situation. An American organisation, the Centers for Disease Control and Prevention, provides concrete risk assessment and management tools and checklists for influenza pandemics (CDC, 2020). Both government agencies and businesses can find tools and advice on their website. When examining these aspects, we analyse the responses that should be provided during crisis management related to the pandemic situation. The $\mathrm{ORX}^{3}-$ an operational risk consortium in the financial sector - has organised weekly consultations for its members during the current pandemic. The consultations provide an opportunity to share best practices all over the world. The next part of this article draws mainly from this valuable source.

Before examining a given company's responses, we analyse the strategic goals the company may set in the current pandemic situation. In addition to immediate and urgent health protection, the three most important objectives are:

3 ORX is the largest operational risk association in the financial sector. It was established in 2002. ORX's goal is to develop a global community of financial institutions and improve management and measurement of operational risk (ORX, 2020d). 
- maintaining business continuity;

- protecting the customer base;

- preserving or even improving the company's reputation.

The road to achieving all three goals leads through well-prepared and well-executed crisis management. The situation is exacerbated by the fact that the current pandemic poses not only an operational risk for companies, but also market, credit and strategic risks. The increased volatility in asset prices, the increase in receivables and the significant decrease in demand for certain products and services further burden market participants struggling to maintain their level of service and to retain customers.

A company needs to be adequately prepared and able to respond to crisis situations in the following three areas:

- operational tasks and responses;

- management tasks and responses;

- communication tasks and responses.

\section{Figure 3}

\section{Crisis management responses}

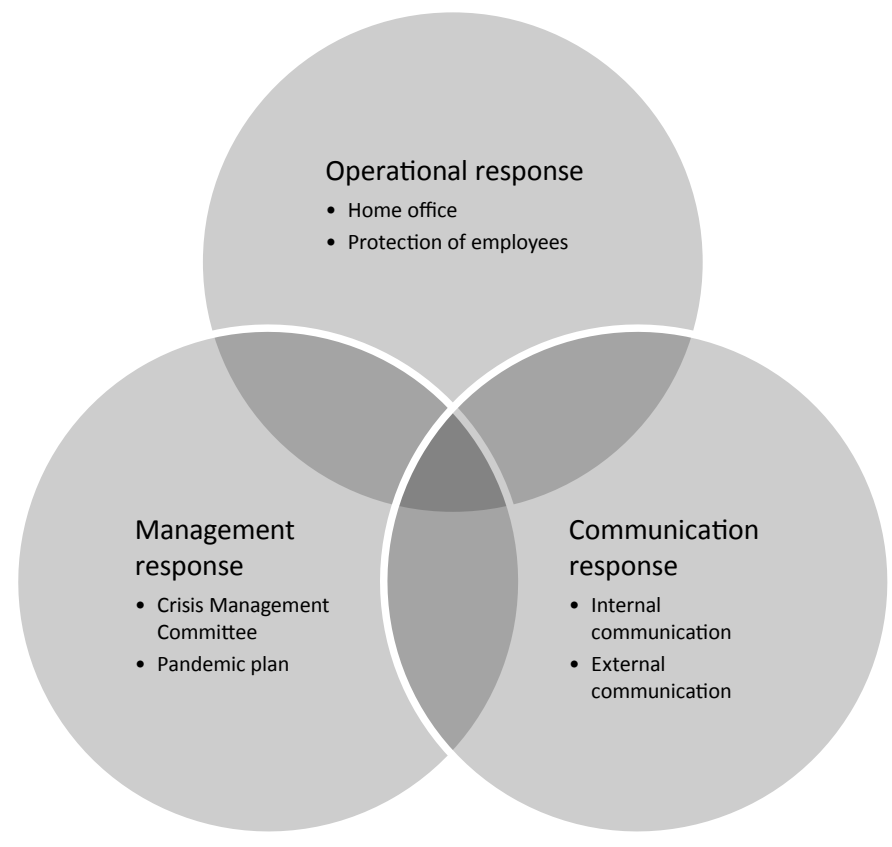

Source: own design 


\subsection{OPERATIONAL RESPONSES TO THE PANDEMIC CRISIS}

Operational responses can be summarized as the set of measures that a company must perform in order to avoid or reduce operational risks which could lead to a crisis event. During a pandemic, a company may face several types of operational risks and scenarios. The most typical are:

- loss of key employees;

- loss of a large number of employees;

- loss of buildings (difficulty in approaching them).

Operational responses also include the implementation of various measures in order to reduce health risks, such as the procurement and distribution of protective tools, masks and disinfectants.

In the case of the banking sector, the maintenance of liquidity management and cash management are among the most important areas.

Accordingly, in the event of a pandemic, both during preparation and after an emergency has occurred, the company needs to think through and answer a plethora of questions.

\subsection{Management responses to the pandemic crisis}

The second group of corporate crisis responses comprises management responses. A management response means putting together a strong, well-prepared, wellinformed and empowered management team that can make the necessary decisions to reduce the negative economic and reputational impact of the crisis.

The management responses required in a pandemic situation are not much different from what is needed in any other crisis. The most important requirement is the development of a pandemic plan, whose execution and - if necessary - modification is coordinated by the crisis management team.

\subsection{Communication responses to the pandemic crisis}

The third group of crisis responses comprises communication responses, including both external and internal communication. With regard to communication, we can also rely on the procedures that can be applied during crisis management: providing one-stop communication, establishing new communication channels or preparing communication templates. 


\section{THE PHASES OF A PANDEMIC CRISIS}

There is no consensus among researchers regarding the different phases of a crisis. Alpaslan et al. (2009) distinguish between two phases of a crisis: the preparation phase and the response phase. Bundy et al. (2016) define three phases: pre-crisis, during the crisis, and post-crisis.

In this study, we use a three-phase approach to analyse corporate responses to a pandemic situation.

Proper crisis management presupposes that the necessary measures are taken both during the preparation period and the ongoing crisis, and that the crisis management system - if necessary - is corrected after the crisis.

In most cases, similar steps are needed at each stage of crisis management, regardless of the nature of the crisis. Now, however, focusing on the pandemic situation, the following table summarises the most important tasks that an organisation must consider at the different stages of crisis management in the event of a pandemic situation. The following lists are based on the recommended content elements of pandemic plans (Department of Enterprise, 2009) and the pandemic protocol and current experience of a large Hungarian bank.

\subsection{Pre-crisis}

We consider the pre-crisis period as the most important part of the process in terms of the options of a company in the case of an actual crisis. According to the internal approach towards crisis management, the most important thing at this stage is to develop crisis management procedures and train the crisis management team psychologically, with regard to both the procedures and communication. In contrast, the external approach emphasizes that the key to proper crisis management preparation is getting to know the stakeholders, developing communication channels with them and shaping their expectations (Bundy et al., 2016). Taking both approaches into account, Table 1 lists the main steps that need to be taken and thought through whilst preparing for a pandemic situation. 
Table 1

\section{Pre-crisis activities}

\section{Internal perspective}

- Appointment of a crisis management team with clearly identified responsibilities

- Gathering information about past pandemics

- Budget plan for a pandemic crisis

- Working out a Business Continuity Plan (BCP)

- Identifying critical processes, employees, inputs

- Nominating and training deputies

- Establishing home office facilities

- Testing the BCP

- Revisiting the BCP regularly

\section{External perspective}

- Consulting with partners, suppliers and other stakeholders

- Considering the impact of suppliers' outage

- Preparation of communication panels and channels

Source: own design

According to Table 1, it is clear that during pandemic preparations we cannot survive without the development of internal processes and responsibilities and the training of crisis team members. It is also evident that nurturing relationships with stakeholders and finding and establishing suitable forms of cooperation with them during the crisis are also of key importance. These preparative measures may include the incorporation of crisis services into partnership agreements, creating communication panels that can be used immediately in a crisis situation, gathering the necessary telephone numbers and e-mail addresses, and establishing good relationships with professional organisations and the media. In a pandemic situation, the solution currently used by most companies is remote working. However, as the suitable conditions for remote working require several months of preparation and significant investment, not all companies have been able to widely implement this solution in the past three months.

At the pre-crisis stage, the most important tasks in the banking sector are:

- preparation of BCPs for management to compensate for the loss of human resources and potential loss of buildings due to quarantine (especially providing branch services, cash supply and liquidity management); 
- procurement of health protection equipment;

- reviewing processes and running projects, and preparing for their re-planning or shutdown;

- continuous monitoring of the pandemic situation;

- preventive communication with stakeholders.

\subsection{During the crisis}

As mentioned earlier, by relying on pre-crisis preparatory steps, during the crisis itself the organisation must address business continuity, crisis management and leadership, as well as external and internal communication.

Table 2 summarizes the most important steps.

Table 2

Activities during the crisis

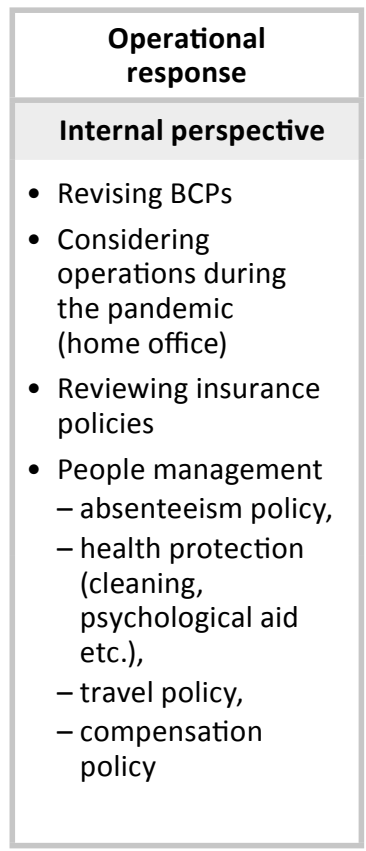

Management
response

\begin{tabular}{|l|}
\hline \multicolumn{1}{|c|}{$\begin{array}{c}\text { Communication } \\
\text { response }\end{array}$} \\
\hline External perspective \\
- Continuous \\
communication \\
with staff about \\
pandemic operations \\
- Communication \\
with other \\
stakeholders \\
(clients, banking \\
associations, \\
supervisor, \\
media etc.) \\
\end{tabular}

Source: own design

In the current pandemic situation, this middle stage could also be divided into several parts, as companies are also phasing out health measures in line with government measures. Operational responses focus primarily on developing 
alternative internal operations. Management responses entail both making the necessary decisions regarding internal operations and coordinating the changes in relation to stakeholders. Communication at this stage of crisis management is the most active both internally and externally. In a pandemic situation, communication and management responses are significantly influenced by government actions and statements, and corporate crisis management can operate in accordance with these.

At this stage, the most important tasks in the banking sector are:

- ensuring compliance with government measures (moratorium, restrictions);

- maintaining business continuity (e.g. shift work);

- protection of the health of workers and customers (installation of plexiglass barriers in branches, distancing, disinfectants, masks, special cleaning provisions, etc.);

- continuous external and internal communication.

\subsection{Post-crisis}

Researchers do not always consider the post-crisis phase as part of crisis management, although at this stage we can learn from mistakes and prepare for the next crisis.

Table 3

\section{Post-crisis activities}

\section{Internal perspective}

- Ensuring the recovery of previous operations

- Evaluation and, if necessary, modification of the crisis management process

\section{External perspective}

- Repairing damage to social perception

Source: own design

According to researchers in favour of the internal approach, organisational and individual learning (especially for managers) are the most important aspects at this stage. On the other hand, supporters of the external approach emphasize the importance of social perception and the efforts made to improve it. In the current 
pandemic situation, the post-crisis stage is especially important because, even once crisis operation is over and we have returned to normal operation, we can still expect to find ourselves in a similar situation again in the autumn. In light of the foreseeable return of the pandemic, the sum of experiences and learning is of crucial importance, making it easier to deal with the similar situation that will follow. Therefore we need to divide the crisis experience into two parts: one part can be integrated into normal operations (crisis-induced digital developments, changes in the work schedule, etc.), while the other part can really help us to survive the next crisis.

\section{CHANGES IN OPERATIONAL RISKS IN THE BANKING SECTOR}

Before focusing only on operational risks, it is important to highlight that the pandemic situation in the banking sector raises not only individual, bank-level risk, but also systemic risk. In addition, we see significant overlaps with market, credit and even strategic risks. The present study focuses on changes in operational risks.

The pandemic situation entails a change in the corporate and banking operational risk portfolio. New types of risks emerge and require special attention and treatment. It is worthwhile monitoring the changes in these risks, to count on them, or even to change early warning systems so that we can filter out the risks as soon as possible and thus prevent them from turning into losses.

Several institutions publish annually the results of surveys about the most significant operational risks of financial institutions, such as ORX (ORX, 2020a) or Risk.net (Risk.net, 2020).

\section{Table 4}

\section{Top ten operational risks in banking (2020)}
1. IT disruption
2. Data compromise
3. Theft and fraud
4. Outsourcing and third-party risk
5. Resilience risk
6. Organisational change
7. Conduct risk
8. Regulatory risk
9. Talent risk
10. Geopolitical risk 
The list published by Risk.net for 2020 includes five risks that are worth highlighting here: geopolitical risk, resilience risk, outsourcing risk, fraud, and cyber risk. According to a January 2020 survey, the risk created by COVID-19 ranks $10^{\text {th }}$ in the list, as part of geopolitical risk. Even then, experts predicted an economic slowdown, falling asset prices and other emerging risks in the banking sector. At that time, COVID-19 fitted into one risk type. Since then, however, the impact of the pandemic has become much broader and has increased the probability of almost all the listed risks.

Resilience risk appeared for the first time on this list among operational risks, ranked $5^{\text {th }}$. Resilience here means how effectively a company can stand up and continue to operate after a major crisis. As the direct crisis caused by COVID-19 and the consequent economic crisis affect all corporate and financial institutions, the resilience of the organisation appears as a kind of selection aspect, a competitive advantage. Therefore, resilience risk deserves an even more prominent place on the list.

Outsourcing risk ranks $4^{\text {th }}$ on the 2020 list. Relationships with partners will be significantly transformed by the current pandemic, and whether partners will be able to continue to operate in the event of a major workforce or building outage will be considered of key importance. As a result, outsourcing risk will probably also increase further compared to the January survey.

Third on the list is theft and fraud. This risk has long been one of the most significant loss-generating operational risks. ORX, an operational risk management professional organisation and data consortium of more than 60 banks worldwide, provides weekly opportunities for its member banks to consult on COVID-19 losses and applicable pandemic procedures. According to their survey, we can expect an increase in losses in the banking sector in terms of both external and internal fraud. The decline in discipline caused by remote working and the economic crisis that has accompanied the pandemic could lead to an increase in credit fraud and other forms of fraud (ORX, 202ob).

Cyber risk appears within the first two risks on the list (IT disruption and data compromise). Increased working at home due to the virus, and the development of vulnerabilities caused by rapid migration and remote work have significantly increased the chances of cyber attacks and the consequent risks of data loss, data theft or system downtime (Marsh \& McLennan, 2020). Cyber criminals see the upheaval, fear and altered functioning of COVID-19 as an opportunity and exploit it, with increased activity in the first two weeks of April, particularly in the field of ransom viruses (Microsoft, 2020).

In addition, the chances of fines in the financial sector may increase because it is not always easy to adapt to fast-changing regulations, whose interpretation in 
many cases is not clear, while non-compliance with the rules and possible deficiencies in the treatment of customers may result in supervisory fines.

In the current phase of the COVID-19 crisis, banks are focusing on the individual risks of employees (psychological and mental health, effectiveness of stress management) and people-related organisational risks (recruitment, retention of skilled labour), which have increased significantly due to remote working (ORX, 2020c).

In order not to report solely on increased risks, we should also mention a risk that, according to a survey by the Control Risk Group, explicitly fell during the pandemic: the risk of kidnapping (Control Risk, 2020). Restrictions on free movement and increased police presence have significantly reduced this threat.

\section{CONCLUSION}

The current pandemic situation caused by COVID-19 can be considered a crisis situation at the individual, company and social level, and needs to be addressed accordingly.

This article dealt with the approaches, tasks and stages of corporate crisis management, highlighting the special tasks of banking sector participants. Every company is obliged to manage a pandemic according to its preparedness and crisis management plan.

The importance of the final phase of crisis management, the learning phase, cannot be over-emphasised, as it allows us to be prepared for a similar crisis situation.

In this case, it is predicted that we will not have to wait years for similar situations to occur, so we can immediately try out all the lessons learned in practice and incorporate them into our plans. The lessons of the COVID-19 crisis need to be broken down into two parts: one part should become part of normal operation (i.e. home office, digitization, etc.), while the other part can improve our crisis management processes.

Crisis responses and solutions sometimes include the possibility of another subsequent crisis. The pandemic has contributed to many changes in the corporate world, especially in banking and operational risk portfolios, and has amplified some risks. Of the increased risks, special attention should be paid to cyber risk, which - as a result of remote working and rapid IT developments - poses an even greater threat than before.

As we are currently in the middle of an ongoing crisis, it is difficult to carry out substantive research and analysis. However, because everything we are learning 
right now becomes immediately usable and can be incorporated into practice, we cannot afford to wait for a clear and transparent situation.

Practitioners need help, guidance and forecasts right now, and rapid research can make a significant contribution to their demands.

\section{REFERENCES}

Alpaslan, Can M. - Green, Sandy E. - Mitroff, Ian I. (2009): Corporate Governance in the Context of Crises: Towards a Stakeholder Theory of Crisis Management. Journal of Contingencies and Crisis Management 17(1), March.

Bachmann, Ruediger - Ehrlich, Gabriel - Ruzic, Dimitrije (2017): Firms and Collective Reputation: The Volkswagen Emission Scandal as a Case Study. CESifo Working Paper, No. 6805, Munich: Center for Economic Studies and Ifo Institute (CESifo).

BBC (2014): RBS fined $£ 56$ m over 'unacceptable' computer failure. 20 November 2014, https://www. bbc.com/news/business-30125728.

BÉLYÁCZ, I. (2013): Várakozások, bizonytalanság, valószínűség [Expectations, uncertainty, probability]. Közgazdasági Szemle, July-August, 749-780.

Bennett, Belinda - Carney, Terry (2015): Planning for pandemics: Lessons from the past decades. Bioethical Inquiry 12, 419-428. DOI: 10.1007/s11673-014-9555-y.

Bundy, Jonathan - Pfarrer, D. Michael - Short, E. Cole - Coombs, W. Timothy (2016): Crises and Crisis Management: Integration, Interpretation, and Research Development. Journal of Management, May, https://media.terry.uga.edu/socrates/publications/2017/03/BundyPfarrerShortCoombsinpress.pdf.

CDC (2020a): Centers for Disease Control and Prevention: influenza risk assessment tools. https:// www.cdc.gov/flu/pandemic-resources/national-strategy/risk-assessment.htm.

CDC (202ob): Centers for Disease Control and Prevention: Past Pandemics. https://www.cdc.gov/flu/ pandemic-resources/basics/past-pandemics.html.

Control Risk (2020): The special risk report. April.

Correia, Sergio - Luck, Stephan - Verner, Emil (2020): Pandemics Depress the Economy, Public Health Interventions Do Not: Evidence from the 1918 Flu (June 5, 2020). Available at SSRN: https://ssrn.com/abstract=3561560 or http://dx.doi.org/10.2139/ssrn.356156o.

Department of Enterprise, Trade and Employment (2009): Business Continuity Planning: Responding to an influenza pandemic, June.

Hendershott, Terrence - Livdan, Dmitry - Schürhoff, Norman (2015): Are institutions informed about news? Journal of Financial Economics 117(2), 249-287.

Johns Hopkins University \& Medicine (2020): COVID-19 Case Tracker, https://coronavirus.jhu.edu/.

Marsh \& McLennan (2020): COVID-19: Evolving insurance and risk management implications. March, https://www.mmc.com/insights/publications/2020/apr/covid-19--evolving-insuranceand-risk-management-implications.html.

McKinsey (2020): COVID Response Center, https://www.mckinsey.com/about-us/covid-responsecenter/home.

Microsoft (2020): Preventing attackers from taking your organization's data ransom. May, https:// news.microsoft.com/apac/2020/05/20/preventing-attackers-from-taking-your-organizationsdata-ransom/. 
ORX (2020a): Operational Risk Horizon 2020. 5 February, https://members.orx.org/orx-publications/operational-risk-horizon-2020.

ORX (2020b): Coronavirus update: 23 April. https://members.orx.org/system/files/2020-04/Coronavirus\%20discussion\%2oreport\%2021\%20April\%202020\%20\%28final\%29.pdf.

ORX (2020c): ORX member discussions on coronavirus: updated 28 May. https://members. orx.org/orx-publications/impact-coronavirus-operational-risk?_hsenc=p2ANqtz-_GaG6MM9SxPLk-xAu3_OhUz6kJVxNBdS4g7TzxiFXh4Nsk5wiDoMiırnL-tiOUUTRM6ShzXilOo3Huq-vNzN6cGGSzgw\&_hsmi=88617068\&utm_campaign=Member\%2onewsletters\&utm content $=88617068 \& u t m \_$medium $=$email\&utm_source $=h s \_e m a i l$

ORX (2020d): ORX Homepage, https://managingrisktogether.orx.org/.

Pearson, M. Christine - Clair, A. Judith (1998): Reframing Crisis Management. Academy of Management Review 23(I), 59-76.

Phillips, BRAD (2013): Eight truths of Crisis Communication. Financial Executive, April.

Risk.net (2020): Top 10 operational risks for 2020. https://www.risk.net/risk-management/7450731/ top-10-operational-risks-for-2020.

Saunders-Hastings, Patrick R. - Krewsio, Daniel (2016): Reviewing the History of Pandemic Influenza: Understanding Patterns of Emergence and Transmission. Pathogens 5(4), 66, DOI:10.3390/pathogens5040066.

Veil, R. Shari - Buehner, Tara - Palenchar, J. Michael (2011): A work-in-process literature review: Incorporating social media in risk and crisis communication. Journal of Contingencies and Crisis Management 9(2), June 110-122.

Wei, Liu - Xiao-Guang Yue - Tchounwou, Paul B. (2020): Response to the Covid-19 epidemic: The Chinese experience and implications to other countries. International Journal of Environmental Research and Public Health 17(7), March, https://www.mdpi.com/1660-4601/17/7/2304. 